\title{
Enhancing the Children's Learning Experience of Mexican Traditions through Augmented Reality ${ }^{\dagger}$
}

\author{
Marcela D. Rodríguez ${ }^{1, *}$, Katherine Caillahua-Castillo ${ }^{2}$, Hector R. Delgado-Valenzuela ${ }^{1}$, \\ Yue H. Zhou ${ }^{1}$ and Ángel G. Andrade ${ }^{1}$ \\ 1 Computer Engineering, Faculty of Engineering, Universidad Autónoma de Baja California, UABC, \\ C.P. 21100 Mexicali, Mexico; delgado.hector@uabc.edu.mx (H.R.D.-V.); zhou.yue@uabc.edu.mx (Y.H.Z.); \\ aandrade@uabc.edu.mx (Á.G.A.) \\ 2 Software Engineering, Faculty of Engineering, Universidad Nacional Mayor de San, Marcos, UNMSM, \\ C.P. 15081 Lima, Perú; katherine.caillahua@gmail.com \\ * Correspondence: marcerod@uabc.edu.mx; Tel.: +52-686-566-4270 \\ + Presented at the 13th International Conference on Ubiquitous Computing and Ambient Intelligence \\ UCAmI 2019, Toledo, Spain, 2-5 December 2019.
}

Published: 20 November 2019

\begin{abstract}
During the "Day of the Dead" celebration in México, altars are installed to commemorate the dead in different places, such as schools' libraries. To preserve this cultural tradition, students visit them to know about the meaning of the altars' elements. In a similar way to museums, children can perceive altars as boring places where they should see objects passively or listen to historical accounts of the past. To address these challenges, we propose using augmented reality to make this cultural tradition a more engaging learning experience. We implemented an augmented reality (AR) prototype which recognizes the altar's elements/objects to present narrative information through video, text, and images. We evaluated it through a within-subjects experiment to test two conditions: (A) A teacher explaining the altar (the usual method), and (B) Using the AR application. For collecting data, we used the User Engagement Scale (UES), a questionnaire to assess children's perception about the learning experience, and observations. From twenty-nine students, only nine perceived that condition A was more engaging than B (augmenting reality). A Wilcoxon Signedranks test indicated a significant difference between both conditions $(W=124.5 ; Z=-2.012 ; p<0.05)$. Our results helped us identify new design features in order for AR support learning experiences about this tradition, such as including narratives through multimedia.
\end{abstract}

Keywords: augmented reality; cultural heritage; learning environment

\section{Introduction}

The syncretism between the Spanish and the pre-Hispanic cultures originated the Day of the Dead celebration in México. Educators have criticized that the teaching of traditions' cultural values in Mexico is limited to the fact that books include related information in a decorative form, or through short descriptions. During the celebration, altars are installed to commemorate the dead in different places, such as the schools' libraries. To preserve the Day of the Dead tradition, students visit altars to know about the meaning of their elements and the life of the commemorated persons. The above mentioned implies that promoting these traditions, mainly in urban areas, is limited to exhibitions carried out only during the festivity days. These exhibitions take place in a short explanatory way about the altars. Therefore, the information that students obtain is not complete enough to be able to understand all the tradition's meanings and elements. The proceedings suggests that complementing this festivity with teaching materials may allow for a broader and more complete vision of the subject. It has been identified that transmitting cultural values of the Day of the Dead, through both, printed 
materials, as well as information transmitted in the family and school environment, allow having a broader and more complete view of the subject analyzed [1]. Also, using interactive information sources increase the attractiveness of the information to convey for the students. Interactive systems may allow students to observe scenes related to this holiday, the ritual, and the altar elements. With this aim, we propose using augmented reality (AR) tablets as complementary teaching material. The broad definition AR states that it is a technology that overlays virtual objects (augmented components) into the real world. These virtual objects seem to coexist in the same space as objects in the real world [2].

Through this technology, children can access the narratives that they cannot perceive directly from objects located on altars. So, we hypothesized that using AR will make this cultural tradition a more engaging learning experience for children. We used the model provided by O'Brien (2018) to understand and assess user engagement, which is defined as: "a quality of user experience characterized by the depth of an actor's cognitive, temporal, affective and behavioral investment when interacting with a digital system" [3]. Our results helped us identify new design features that support students learning experiences about this tradition.

The rest of this paper is structured as follows: Section 2 presents related work to investigations on augmenting reality in education. Section 3 presents the AR system developed so far. Section 4 describes the methodology followed to assess our system. Section 5 shows the evaluation's results. Section 6 presents our conclusions and future work.

\section{Related Work}

The variety of multimedia formats that can be used to convey learning content in AR applications makes this approach attractive to be explored in different educational settings. Thus, prior works have studied the effect on the learning and user experience of AR-based applications [46]. It has been found that their effects vary depending on the particular knowledge to be conveyed and the unique design of the AR experience. For instance, for learning spatial structures and functions such as chemical and astronomy configurations, students show more significant learning than using only their textbooks $[7,8]$. In contrast, another study contrasted children's learning of astronomy when using a PC-based application and a mixed-reality (MR) application; with the MR app, children tend to focus on the dynamics of planet movements, while with the PC-app they focus on the surface details of planets [9]. On the other hand, multiple papers have demonstrated that factors associated with user experience are enhanced with AR apps, e.g., motivation, engagement, and enjoyment [5]. So, according to previous research, it is difficult to identify what types of content can be effectively taught using AR and which is difficult [5].

\section{System Deployment}

To assess the feasibility of our approach and to find out the characteristics of the AR system, we developed a prototype for Android tablets and conducted an in-situ evaluation. As illustrated in Figure 1a, it consisted of a simple user interface that, when the camera was focused on an element of the altar, it presented a short narrative of the origin of the element and a video or image describing its meaning (see Figure 1b). 


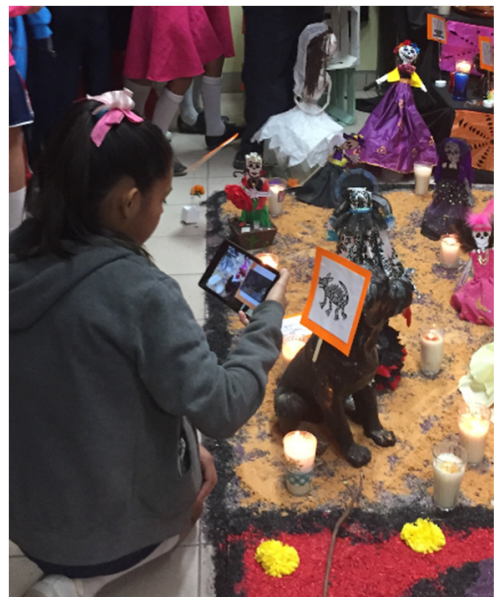

(a)

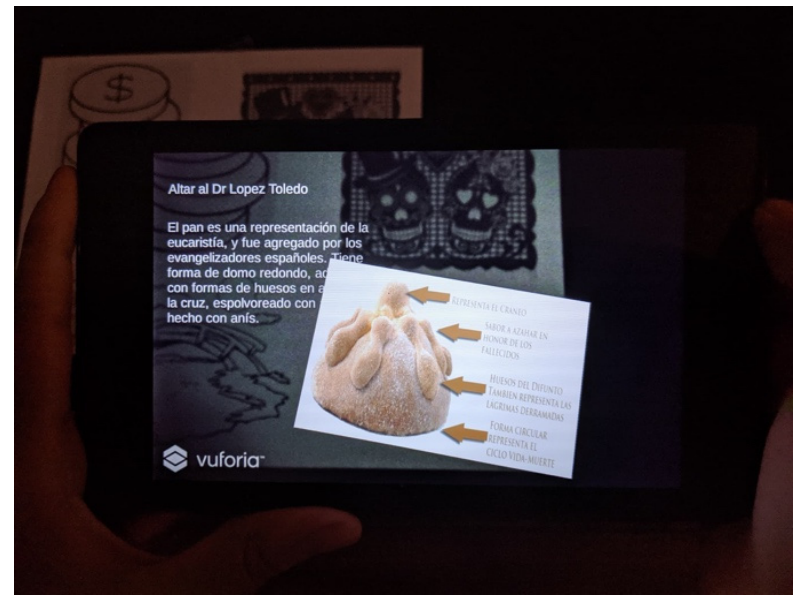

(b)

Figure 1. Augmented reality prototype's functionality: (a) A user is focusing a tag attached to an altar's element; (b) Narrative and image presented for the element selected.

For conducting the evaluation, we generated 15 printed tags to be recognized through the system; four were used to explain who was the commemorated person and 11 to explain common altars' elements. The tags were attached to the corresponding elements, as shown in Figure 1a. Table 1 presents some of these tags and the narrative and images presented through AR.

Table 1. Some the elements' tags of the altar and the multimedia information presented through Augmented reality (AR).

Narrative
incinerating the deceased, a dog was
sacrificed to accompany him/her and take
care in him/her journey to the Mictlán,
where felines could attack them.
The rod helps the deceased and the dog
defend themselves against temptations and
threats that arise along the way.
$\begin{gathered}\text { Dr. Jesús López Toledo is remembered for } \\ \text { his great vocation to train high-quality } \\ \text { teachers. He was a critic of the bad practices } \\ \text { of teaching work. He received several } \\ \text { awards, both for his teaching and for his } \\ \text { literary work. He was the founder of the } \\ \text { National Pedagogical University. }\end{gathered}$

\section{Study Design}

\subsection{Aim of the Study}

This study aims to find out how the students' experience using the AR prototype affects the learning and appreciation of the cultural value of the Day of the Dead altar tradition. To pursue this objective, we designed an experiment to test the following hypothesis: 
Hypothesis 1. Participants perceive that the AR prototype improves their learning experience about the tradition.

Hypothesis 2. The AR prototype increments their engagement for learning about the tradition.

\subsection{Study Method}

The study was conducted in a public middle school of our municipality, on 31 October 2018, since altars are used to be installed before the festivity day (2 November). Before the study, we talked with some of the schools' teachers to get information about how they were building the altar. We realized that they and the students plan how to design the altar in advance. For instance, they decide who dedicate the altar to, the objects to include, and how to obtain or make them. Once we obtained information of the altar that they were building, we tailored the system to show information about the elements included in that altar.

We designed a within-subjects crossover study to test two conditions that help children understand the meaning of altar elements:

- Condition A: Listening to the teacher's explanation of the altar's elements. This is the usual method used in schools. As illustrated in Figure 2a, the teacher explains to the group of students the altars' meaning and whom the person commemorated is.

- Condition B: Using the AR prototype to get information about the altar's elements (see Figure $2 \mathrm{~b}$ and $2 \mathrm{c})$.

The crossover-based method was used to cope with the learning transferring between conditions. The study consisted in a 2-h session in which half of the students first participated in the condition A, and afterward, in B; we repeated the evaluation process with the second half of the group who first participated in the condition $\mathrm{B}$, and then in $\mathrm{A}$.

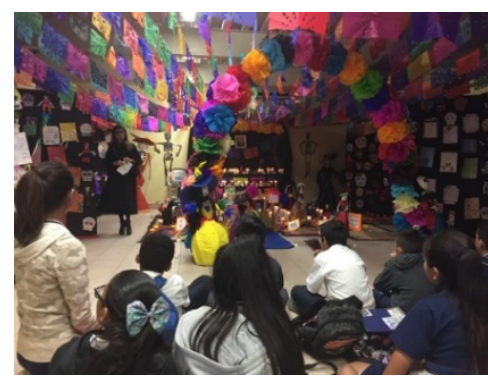

(a)

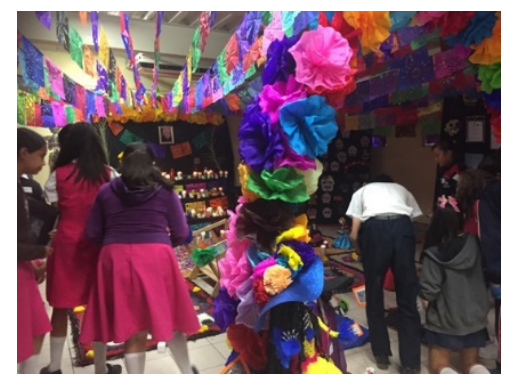

(b)

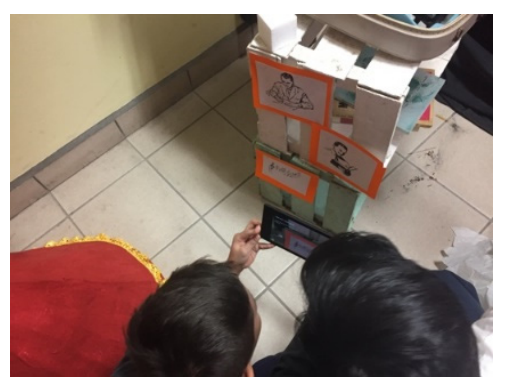

(c)

Figure 2. Study session: (a) Teacher explaining the meaning of the altars' elements; (b) students using the prototype; and (c) children learning about the person to whom the altar was dedicated.

\subsection{Data Collection and Analysis}

At the beginning of the session, all the students answered an initial questionnaire about their previous experience with augmented reality. After participating in each condition, they answered the set of instruments presented in Table 2:

1. The User Engagement Scale (UES) [3]. Participants were instructed to reflect on their experience of engaging with the condition used. The instrument consists of twelve items distributed in four dimensions: Focused attention (FA), perceived usability (PU), aesthetic appeal (AE), and rewarding $(\mathrm{RW})$.

2. A questionnaire with 10 items that we designed to assess children's learning experience.

We implemented the instruments with google forms. After finishing using each condition, participants accessed the instruments to score each of their items through a five-point Likert scale (strongly disagree-strongly agree). Our data collection was complemented with observations that we 
made during the use of the system. Two of the co-authors of this papers conducted non- participative observations by taking notes.

We used Wilcoxon matched-pairs signed ranks test and the SPSS tool to find significant differences in learning experience and engagement between the study conditions, for which we compared the $P$-value with a significance level set to $0.05[10,11]$.

Table 2. Items of the instruments used to collect data about users' experience.

\begin{tabular}{|c|c|}
\hline Learning Experience & User Engagement Scale (UES) \\
\hline 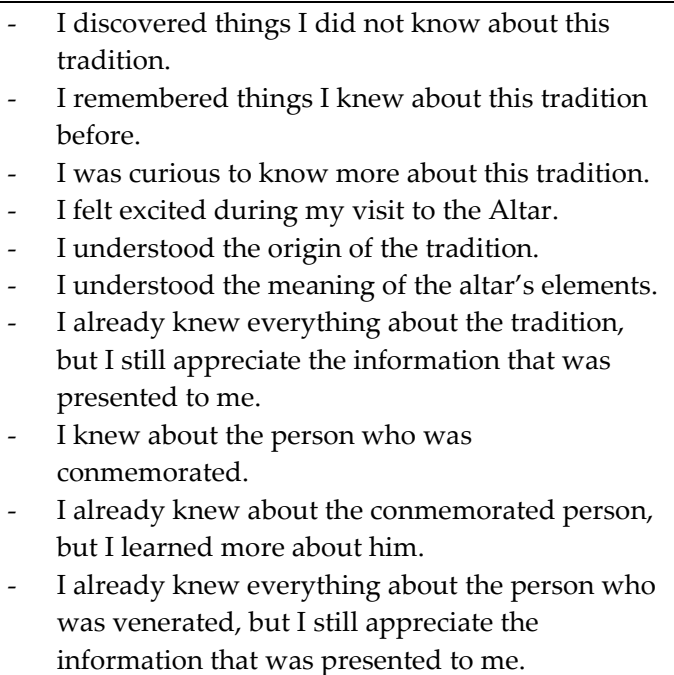 & $\begin{array}{l}\text { FA-S.1 I lost myself in this experience. }{ }^{1} \\
\text { FA-S.2 The time I spent [condition A/B] just slipped away. } \\
\text { FA-S.3 I was absorbed in this experience. } \\
\text { PU-S.1 I felt frustrated while [condition A/B]. }{ }^{1} \\
\text { PU-S.2 I found [condition A/B] confusing to use/understand. }{ }^{1} \\
\text { PU-S.3 [condition A/B] was taxing. }{ }^{1} \\
\text { AE-S.1 [condition A/B] was attractive. } \\
\text { AE-S.2 [condition A/B] was aesthetically appealing. } \\
\text { AE-S.3 [condition A/B] appealed to my senses. } \\
\text { RW-S.1 [condition A/B] was worthwhile. } \\
\text { RW-S.2 My experience was rewarding. } \\
\text { RW-S.3 I felt interested in this experience. }\end{array}$ \\
\hline
\end{tabular}

${ }^{1}$ The scores were inverted for these items as indicated by the instrument instructions.

\section{Results}

\subsection{Participants}

Participants were 14 men and 15 women aged 11 to 13 years $(M=11.68 ; S D=0.54)$. Twelve (12/29) of them stated that they knew what AR is, and five of them reported using AR in video games. Figure 3 and Figure 4 show, respectively, the participants' responses to the learning experience (LE) and user engagement (UES) instruments for each condition (A and B).

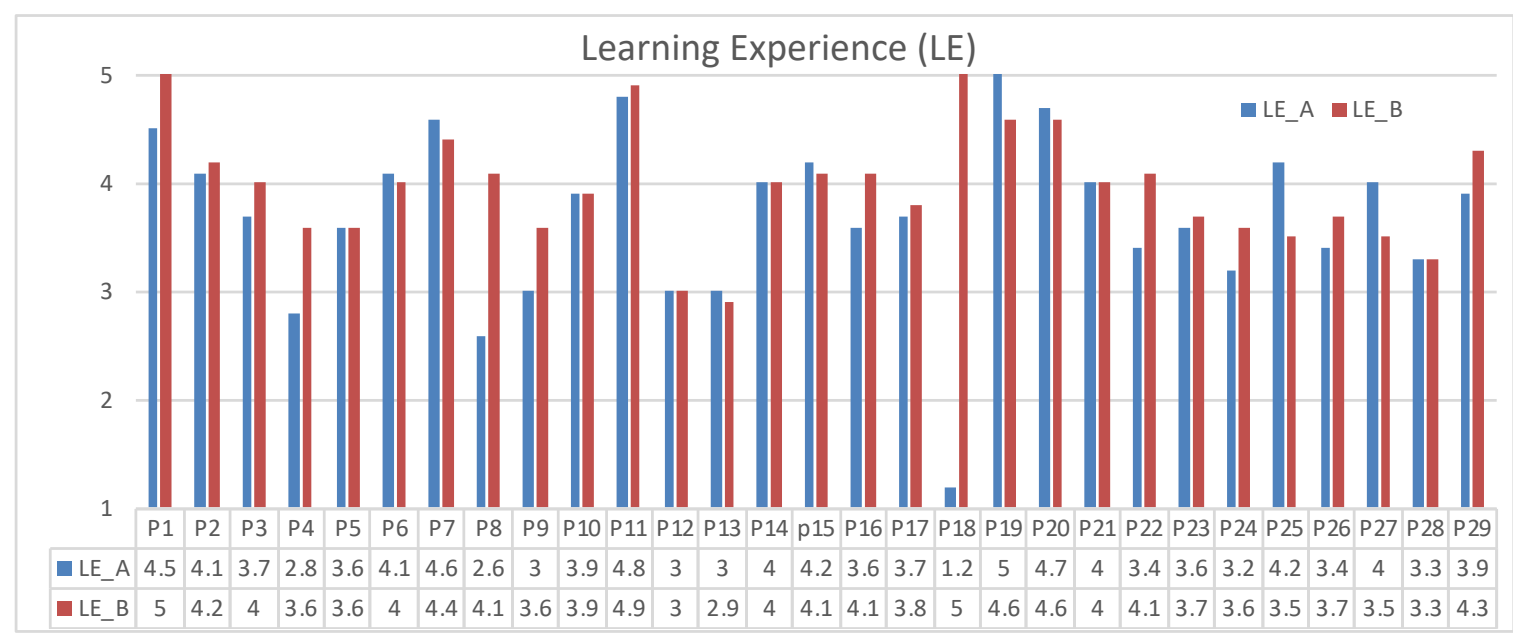

Figure 3. Data collected from the learning experience (LE) instrument. 


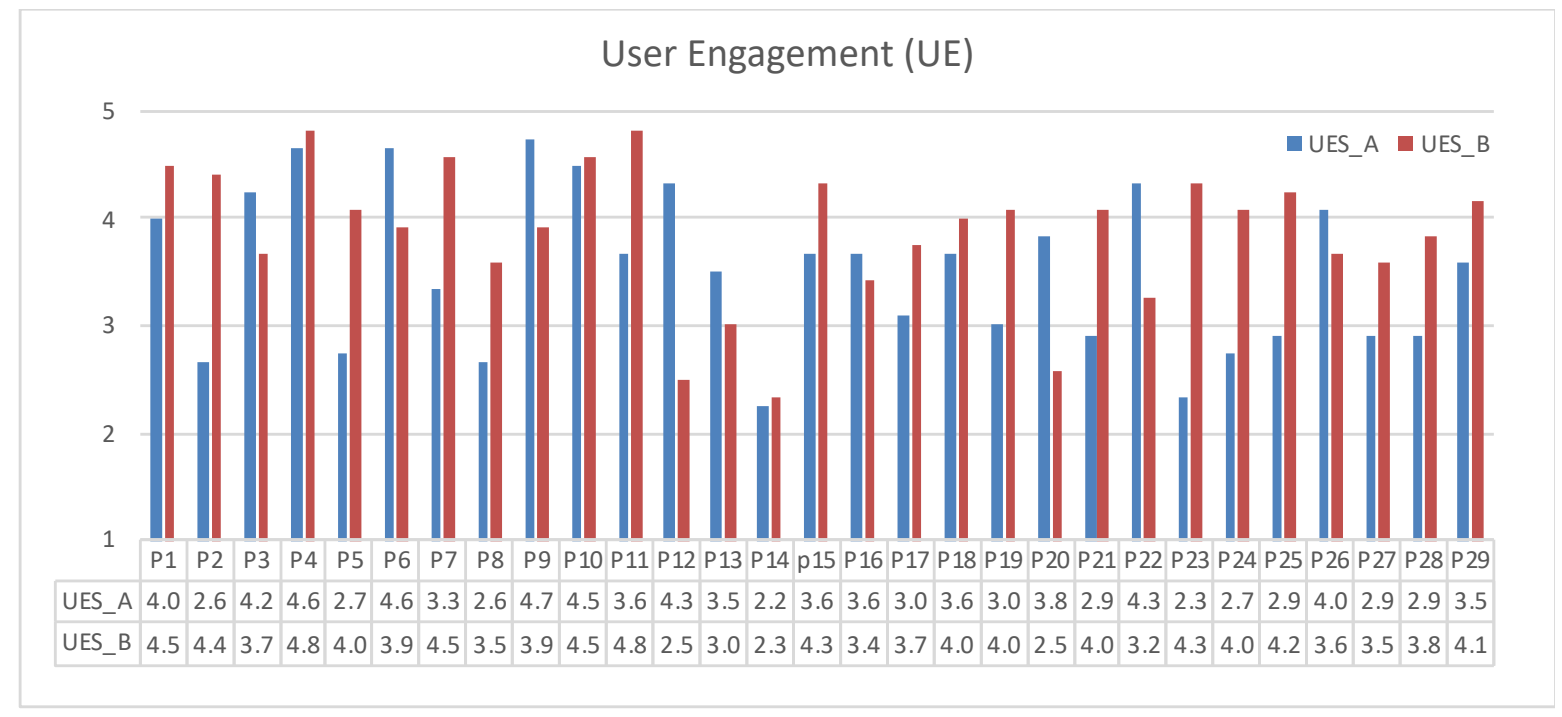

Figure 4. Data collected from the User Engagement Scale (UES) instrument.

\subsection{Perception of Learning Experience (LE)}

As illustrated in Figure 3, most of the students perceived that condition B (the AR) increased more their learning experience than condition A (teacher's explanation). The medians obtained for condition $\mathrm{A}$ and $\mathrm{B}$ were 3.7 and 4, respectively. We obtained that the test discarded the six participants that obtained the same score in both conditions (see Figure 3), so the $N$ was reduced to 23. The estimated value of $W$ is 75.5, and the critical value for $W$ at $N=23$ is 83 . Even though this result is significant at $P<0.05$, the signed test indicates that the value of $Z$ is -1.911 and that this result is not significant at $P_{2 \text { tails }}=0.056$.

\subsection{User Engagement (UE)}

From the data collected through the UES (see Figure 4), we obtained that the medians for condition A and B were 3.58 and 4, respectively. We obtained that the value of $W$ was 124.5 , and that the critical value for $W$ at $N=29$ is 126 . Therefore, the result of $W$ is significant at $P<0.05$. Additionally, the signed test reveals that the value of $Z$ is -2.012 , and that this result is significant at $P_{2}$ tails $=0.044$. We are able to conclude that using AR increments the user engagement for learning about the altars' elements.

\subsection{Observed Users' Reactions}

During the use of the prototype, participants interchange comments about the system. Some of them suggested their peers visit some of the altar's elements to watch some images/videos that most call their attention. We noticed that watching videos showing some animations explaining the elements were those that most liked them. These students' actions are evidence that the prototype enabled them to navigate freely through the altar's elements while interacting with their peers to discuss information discovered through the AR. Additionally, we observed that students enjoyed using the prototype as a tool to learn about this tradition.

\subsection{System Requirements}

Based on what we learned about how school teachers and students participate in the planning process of the altar building, and our observations during the session, we propose the following design requirements that may improve our AR prototype:

- Enrich the narratives through multimedia, especially through visual narrative representations since they were the most appreciated by the participants during the evaluation session. 
- Incorporate design features of narrative games to improve the playfulness of the AR. For instance, including a character (the deceased person) in the narratives, who made specific actions with the elements presented on the altar.

- Include a component to enable professors and students to tailor the AR system to present information about their altar design. We consider that this functionality could be used during the planning process of the altar, which may support the collaboration among the students.

\section{Conclusions and Future Work}

Our results provided evidence that the students' engagement is incremented through the AR system. We consider that this technology could be an appropriate means for complementing the information provided by teachers. In this paper, we provide quantitative evidence about how children perceived that AR improves their engagement for learning about cultural traditions. We observed that the AR prototype enabled students to navigate freely through the altar's elements while interacting with their peers to discuss information discovered through the AR. Our results helped to identify new system's design features to improve the learning experiences about the tradition, such as collaborative features to support the design process of altars.

A limitation of the study is that our data collection methods were based on auto-reporting and non-participative observations. Both of these techniques did not enable us to gather evidence about the knowledge that they acquire from each condition. Besides, we were not able to obtain more information about what design features they most liked or disliked of our AR prototype.

As future work, we plan to build the next version of the AR to address the previous-mentioned requirements and evaluate the new features. Additionally, we plan to use other techniques and instruments for assessing the effect of AR on the learning about this tradition, such as semi-structured interviews.

Acknowledgments: We thank to the Middle School for their availability for conducting the study.

Conflicts of Interest: The authors declare no conflict of interest.

\section{References}

1. Kyriakou, P.; Hermon, S. Can I touch this? Using Natural Interaction in a Museum Augmented Reality System. Digit. Appl. Archaeol. Cult. Herit. 2019, 12, e00088, doi:10.1016/j.daach.2018.e00088.

2. Azuma, R.T. A survey of augmented reality. Presence: Teleoper. Virtual Environ. 1997, 6, 355-385, doi:10.1162/pres.1997.6.4.355.

3. O'Brien, H.L.; Cairns, P.; Hall, M. A practical approach to measuring user engagement with the refined user engagement scale (UES) and new UES short form. Int. J. Hum.-Comput. Stud. 2018, 112, 28-39, doi:10.1016/J.IJHCS.2018.01.004.

4. Wu, H.-K.; Lee, W.-Y.; Chang, H.-Y.; Liang, J.-C. Current status, opportunities and challenges of augmented reality in education. Comput. Educ. 2013, 62, 41-49, doi:10.1016/J.COMPEDU.2012.10.024.

5. Radu, I. Augmented reality in education: A meta-review and cross-media analysis. Pers. Ubiquitous Comput. 2014, 18, 1533-1543, doi:10.1007/s00779-013-0747-y.

6. Akçayır, M.; Akçayır, G. Advantages and challenges associated with augmented reality for education: A systematic review of the literature. Educ. Res. Rev. 2017, 20, 1-11, doi:10.1016/J.EDUREV.2016.11.002.

7. Sin, A.K.; Zaman, H.B. Live Solar System (LSS): Evaluation of an Augmented Reality book-based educational tool. In Proceedings of the 2010 International Symposium on Information Technology (ISIT 2010), Kuala Lumpur, Malaysia, 15-17 June 2010; pp. 1-6.

8. Chen, Y.-C. A study of comparing the use of augmented reality and physical models in chemistry education. In Proceedings of the 2006 ACM International Conference on Virtual Reality Continuum and Its Applications (VRCIA 2006), Hong Kong, China, 14-17 June 2006; pp. 369-372.

9. Lindgren, R.; Moshell, J.M. Supporting children's learning with body-based metaphors in a mixed reality environment. In Proceedings of the 10th International Conference on Interaction Design and Children (IDC 2011), Ann Harbor, MI, USA, 20-23 June 2011; pp. 177-180. 
10. SPSS Statistics-Visión General-MéxicolIBM. (n.d.). Available online: https://www.ibm.com/mxes/products/spss-statistics (accessed on 20 July 2019).

11. Pagano, R. Understanding Statistics in the Behavioral Sciences, 10th ed.; Wadsworth/Cengage Learning: Belmont, CA, USA, 2013; ISBN 13-978-1-111-83726-6. 